\title{
BMJ Cancer risk with folic acid supplements: OPen a systematic review and meta-analysis
}

\author{
Tale Norbye Wien, ${ }^{1}$ Eva Pike, ${ }^{1}$ Torbjørn Wisløff, ${ }^{1}$ Annetine Staff, ${ }^{2,3}$
} Sigbjørn Smeland, ${ }^{3,4}$ Marianne Klemp ${ }^{1}$

To cite: Wien TN, Pike E, Wisløff $\mathrm{T}$, et al. Cancer risk with folic acid supplements: a systematic review and meta-analysis. BMJ Open 2012;2:e000653.

doi:10.1136/

bmjopen-2011-000653

- Prepublication history and additional material for this paper are available online. To view these files please visit the journal online (http:// bmjopen.bmj.com).

Received 19 November 2011 Accepted 1 December 2011

This final article is available for use under the terms of the Creative Commons Attribution Non-Commercial 2.0 Licence; see http://bmjopen.bmj.com

${ }^{1}$ Norwegian Knowledge Centre for the Health Services, Oslo, Norway ${ }^{2}$ Department of Obstetrics and Department of Gynaecology, Oslo University Hospital, Oslo, Norway ${ }^{3}$ Institute for Clinical Medicine, Faculty of Medicine, University of Oslo, Oslo, Norway

${ }^{4}$ Division of Surgery and Cancer Medicine, Oslo University Hospital, Oslo, Norway

Correspondence to Dr Marianne Klemp; marianne.klemp@nokc.no

\section{ABSTRACT}

Objective: To explore if there is an increased cancer risk associated with folic acid supplements given orally.

Design: Systematic review and meta-analysis of controlled studies of folic acid supplementation in humans reporting cancer incidence and/or cancer mortality. Studies on folic acid fortification of foods were not included.

Data sources: Cochrane Library, Medline, Embase and Centre of Reviews and Dissemination, clinical trial registries and hand-searching of key journals.

Results: From 4104 potential references, 19 studies contributed data to our meta-analyses, including 12 randomised controlled trials (RCTs). Meta-analysis of the 10 RCTs reporting overall cancer incidence ( $N=38233$ ) gave an $R R$ of developing cancer in patients randomised to folic acid supplements of 1.07 (95\% Cl 1.00 to 1.14$)$ compared to controls. Overall cancer incidence was not reported in the seven observational studies. Meta-analyses of six RCTs reporting prostate cancer incidence showed an RR of prostate cancer of $1.24(95 \% \mathrm{Cl} 1.03$ to 1.49$)$ for the men receiving folic acid compared to controls. No significant difference in cancer incidence was shown between groups receiving folic acid and placebo/ control group, for any other cancer type. Total cancer mortality was reported in six RCTs, and a metaanalysis of these did not show any significant difference in cancer mortality in folic acid supplemented groups compared to controls (RR 1.09, $95 \% \mathrm{Cl} 0.90$ to 1.30$)$. None of the observational studies addressed mortality.

Conclusions: A meta-analysis of 10 RCTs showed a borderline significant increase in frequency of overall cancer in the folic acid group compared to controls. Overall cancer incidence was not reported in the seven observational studies. Prostate cancer was the only cancer type found to be increased after folic acid supplementation (meta-analyses of six RCTs). Prospective studies of cancer development in populations where food is fortified with folic acid could indicate whether fortification similar to supplementation moderately increases prostate cancer risk.

\section{INTRODUCTION}

Folic acid is a synthetic form of the essential B vitamin folate, also named folacin, pteroylglutamic acid or vitamin B9. Folic acid is

\section{ARTICLE SUMMARY}

\section{Article focus}

- The present systematic review aims to explore if there is an increased cancer risk associated with folic acid supplements given orally.

\section{Key messages}

- Meta-analysis of 10 RCTs showed no benefit but a borderline significant increase in incidence of overall cancer in the folic acid group compared to controls. Overall cancer incidence was not reported in the seven observational studies. When analysing site-specific cancers, prostate cancer was the only cancer type where an increase in risk was shown for folic acid supplements.

n The current study does not show any evidence for augmented cancer risk for fertile women who are recommended folic acid periconceptionally in order to reduce the risk of neural tube defects.

Strengths and limitations of this study

- This systematic review has been performed with a thorough systematic search; and data extraction and quality assessment have been performed by at least two independent persons.

- The limited time of follow-up of most RCTs is a limitation of our review because the time frame for cancer development might exceed the followup time in many RCTs.

- The highly selected population in which most of the studies were conducted limits the applicability to the general population and women of childbearing age taking folic acid periconceptionally.

in the human body converted to 5-methyltetrahydrofolate, which also is the form of folate found in dietary sources and is particularly abundant in vegetables, fruits and grains. Folic acid is more stable than 5methyltetrahydrofolate, which is highly labile and sensitive to oxidation. Folate is involved in synthesis, repair and methylation of DNA, and folate deficiency may lead to developmental and degenerative conditions, such as neural tube defects in developing embryos and megaloblastic anaemia at any age. Folic acid supplements are widely used to prevent 
and treat folate deficiency in groups at risk and also to prevent adverse events associated with antifolate medication. In Norway, folic acid is among the 10 most sold non-prescription drugs with 17.5 defined daily doses per 1000 inhabitants/day. ${ }^{1}$ Folic acid supplements may be administered in various forms, such as tablets, mixtures or intravenously. In addition, folic acid may be added to foods as fortification of, for example, grains and cereals. The rationale for folic acid fortification is prevention of neural tube defects in developing embryos, and this policy is advocated in several countries around the world (such as in the USA and Canada) but not in Norway or in the UK.

Fertile women are a large population group who are recommended to take daily folic acid supplements, starting the month before conception and lasting throughout the first trimester in order to prevent possible neural tube defects in developing embryos. Folate has also been widely used in patients with cardiovascular diseases because it lowers homocysteine, which has been associated with increased risk of cardiovascular events. ${ }^{2}$ Recent data from meta-analyses, however, do not show benefit of folic acid supplementation on risk for cardiovascular events. $^{3-5}$

Masking of vitamin $\mathrm{B}_{12}$ deficiency, with risk of irreversible nerve damage, is a well-known risk associated with folic acid supplementation, especially in the older population. ${ }^{6}$ In general, however, folic acid supplementation has been considered safe. Foods containing folate possibly decrease the risk of several cancers. ${ }^{7}$ Folate is involved in the synthesis of nucleotides and amino acids, including methonine. In folic acid deficiency, the primary intracellular methyl donor S-adenosylmethionine is reduced, and synthesis, methylation and repair of DNA are hampered and the resulting DNA instability increases the risk of cancer development. ${ }^{8}{ }^{9}$ Over the past years, however, there have been rising concerns that folic acid supplementation actually could increase the risk of cancer, as animal and human studies have indicated that high folate status might promote progression of preneoplastic and undiagnosed neoplastic lesions. ${ }^{10} 11$ A combined analysis from $2009^{12}$ of two Norwegian randomised controlled clinical trials, ${ }^{13}{ }^{14}$ with extended post-trial follow-up, demonstrated an increased incidence of cancer among patients taking folic acid for homocysteine reduction as secondary prevention of cardiovascular events.

The aim of the present systematic review was to investigate whether folic acid supplement given orally increases cancer incidence and cancer mortality in humans. Risks associated with folic acid fortification of foods are beyond the scope of this review.

\section{METHODS}

We conducted a systematic review and several metaanalyses of existing literature, following the methods recommended in the PRISMA statement for reporting systematic reviews and meta-analyses of studies that evaluate healthcare interventions. ${ }^{15}$ The methods of the analyses and inclusion criteria were prespecified and published in a protocol available at the web pages of the Norwegian Knowledge Centre for the Health Services and are available as online supplementary materials. ${ }^{16}$

\section{Eligibility criteria}

We included systematic reviews, randomised controlled trials (RCTs) and controlled observational studies (case-control and cohort studies) that assessed cancer incidence and/or cancer mortality in any population taking folic acid supplements $\geq 0.4 \mathrm{mg} /$ day by oral route for any indication. Folic acid could be taken with or without other B vitamins and compared with any control. We excluded studies where folic acid was given as part of high-dose cytostatic regimen of cancer treatment. The folic acid dose cut-off of $\geq 0.4 \mathrm{mg} /$ day was set in order to compare doses considered to have clinical relevance across groups and studies.

\section{Literature search}

To identify all relevant published reports, we performed a systematic literature search using medical subject headings $(\mathrm{MeSH})$ and free-text search terms for folate, folic acid, cancer and neoplasm. We searched the following electronic databases and web pages from inception to present: Embase, Ovid Medline, Cochrane Library, Centre for Reviews and Dissemination, NHS evidence, Clinical evidence and ISI Web of Knowledge, AHRQ, INAHTA, SBU, DACEHTA and FINOHTA. The searches were conducted in March 2010, with supplementary searches in Embase, Medline and Cochrane Library on 6 May 2010. A filter for controlled studies was used in order to reduce number of hits. ${ }^{17}$ There were no limits by language, and non-English papers with a relevant English abstract were translated. The full search strategy including the search terms for the various databases is supplied at the web pages of the Norwegian Knowledge Centre for the Health Services. ${ }^{18}$ In addition, we manually searched reference lists of review articles and conducted limited updated non-systematic literature searches in the same electronic databases up to 31 January 2011. For ongoing studies, we searched WHO's International clinical trials registry platform and http://www.clinicaltrials.org, up to 10 February 2011. Study authors were not contacted for additional non-published data.

\section{Data extraction and quality assessment}

All citations identified by the search process were screened by two reviewers independently (TNW and EP) to determine if they met the eligibility criteria. Possible relevant articles were retrieved in full text. To avoid missing studies due to inconsistent vocabulary (folic acid/folate), citations on dietary folate were also retrieved in full text and assessed.

The quality of the included studies was assessed independently by two reviewers (TNW and EP) using the Cochrane Collaboration's tool for Risk of Bias 
assessment ${ }^{19}$ for RCT's and checklists for cohort and case-control studies. ${ }^{20}$ The quality of the end points was assessed by the same two reviewers using GRADE. ${ }^{21}$ Study data were extracted using standardised tables by three authors independently (TNW, EP and TW) and were always extracted from the intention-to-treat populations. Any disagreements between the independent assessments of the reviewers in literature selection, data extraction and quality assessment were dissolved by discussion or by a fourth reviewer (MK).

\section{Statistical analyses}

When feasible, we pooled data by meta-analyses with Cochrane Collaboration software (RevMan5) and used random-effects model calculating RRs with 95\% CIs. For trials with factorial design, we compared all groups that received folic acid supplements $\geq 0.4 \mathrm{mg}$ /day with groups that did not. Analyses were conducted for both crude data and adjusted data when possible. For RCT's, analyses of crude data are presented in this article, and for observational data, adjusted analyses are presented. In our analyses of adjusted data, we used the analyses with the most explanatory variables if there were alternatives. These analyses were combined using generic inverse variance in RevMan5. Sensitivity analyses were predefined for population characteristics such as sex, age, body mass index, comorbidity and risk factors for cancer such as smoking habits and characteristics of intervention such as dose and time of exposure and time to outcome assessment, that is, time of follow-up. As individual patient data were not available, sensitivity analyses were performed at trial level.

\section{RESULTS}

\section{Literature search and characteristics of included studies}

The literature search retrieved 4104 citations, and additionally 31 citations were identified through manual searches of reference lists and limited updated searches. Fourteen articles from the literature search and seven articles from the manual search, together covering 19 studies, were included (figure 1). The 19 included studies represented 12 RCTs and seven observational studies (six cohort studies and one case-control study). Details of the included RCTs are given in table 1 and of the observational studies in table 2. All RCTs were performed between 1994 and 2008, except for one study, a 36-year follow-up of an RCT of folic acid given in pregnancy, starting in 1966. ${ }^{29}{ }^{30}$ Baseline dietary data in the observational studies were collected between 1984 and 1986 in the Nurses' Health Study and Health Professionals Follow-up Study ${ }^{36}$ and up to 2000-2002 in the VITamins And Lifestyle (VITAL) Cohort Study. ${ }^{34} 38$ Seven RCTs were performed in populations with cardiovascular disease or high-risk groups for cardiovascular disease, three were in populations with a history of colorectal adenoma, one in a population with atrophic gastritis and one was performed in pregnant women. Except for a cohort study in patients with ulcerative

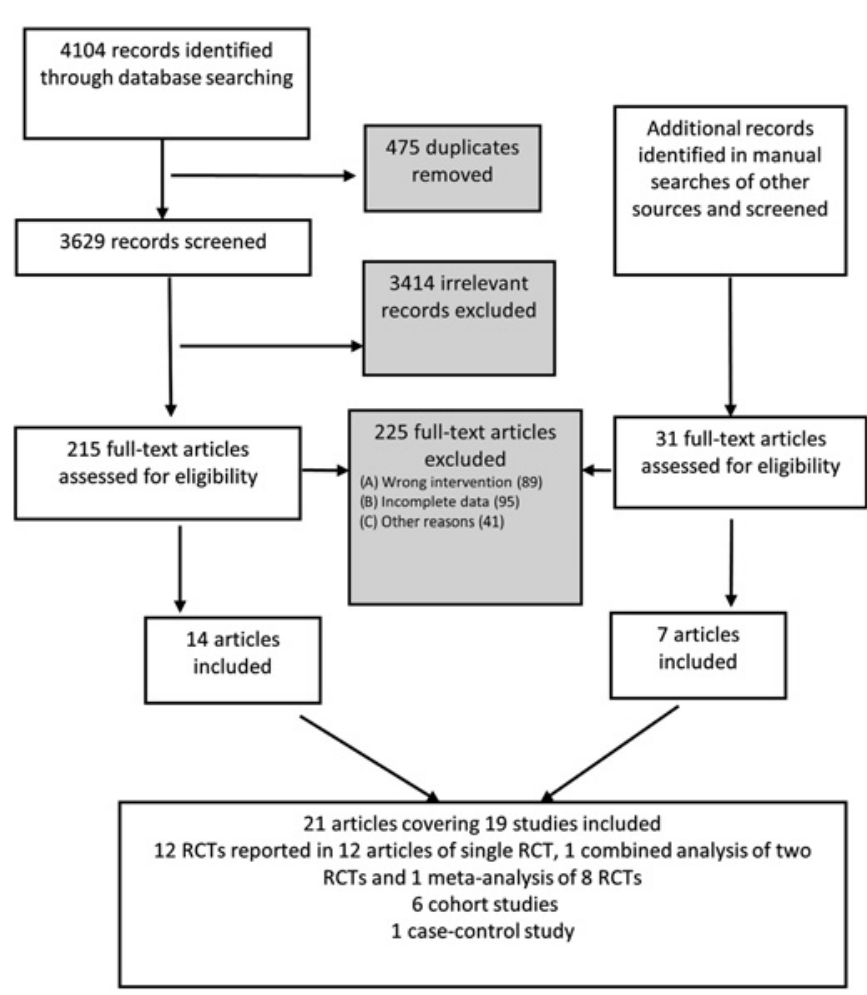

Figure 1 Process of study selection. RCT, randomised controlled trial.

colitis, ${ }^{35}$ the populations in the observational studies were not selected by any morbidity criteria but were rather cohorts/case-control studies selected by living area or profession. All folic acid supplements were administered as tablets, and in many of the RCTs given in combinations with other interventions (table 1). Two RCTs (NORVIT ${ }^{13}$ and WENBIT ${ }^{14}$ with a median of 40 and 38 months treatment, respectively) reported cancer data of an additional 38 months post-trial observational follow-up in a combined analysis published in $2009 .{ }^{12} \mathrm{We}$ have in our meta-analysis used data from the combined analysis stratified by trial but refer to the original publications $^{13}{ }^{14}$ and count these studies (NORVIT and WENBIT) as two RCTs. Two RCTs, HOST ${ }^{24}$ and VISP, ${ }^{25}$ did not report cancer data in the original publications, but such data are provided in a recent meta-analysis from which we have extracted cancer data. ${ }^{3}$

When available, analyses were performed on adjusted data in addition to crude data. These analyses gave the same conclusions. For the RCTs, we present crude data in text and figures (adjusted data are available at the web pages of the Norwegian Knowledge Centre for the Health Services ${ }^{18}$ ).

\section{Ongoing studies}

Our search for ongoing and unpublished studies with the search word 'folic acid' detected 1642 studies in WHO's International clinical trials registry platform and 245 trials in the http://ClinicalTrials.gov database. Only two of these trials met our eligibility criteria including cancer as predefined outcome. One is an ongoing Dutch study of vitamin B12 and folic acid supplementation for 

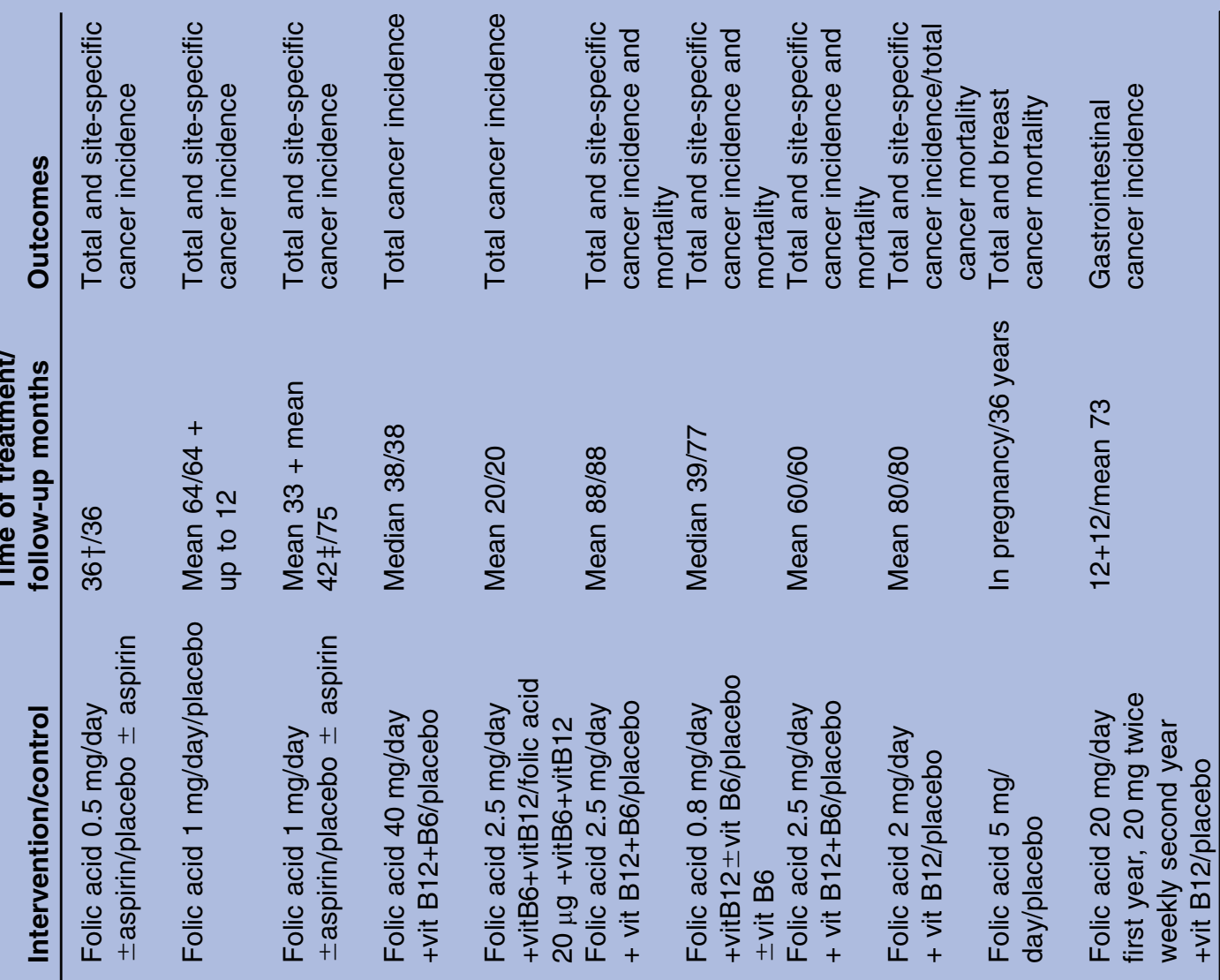

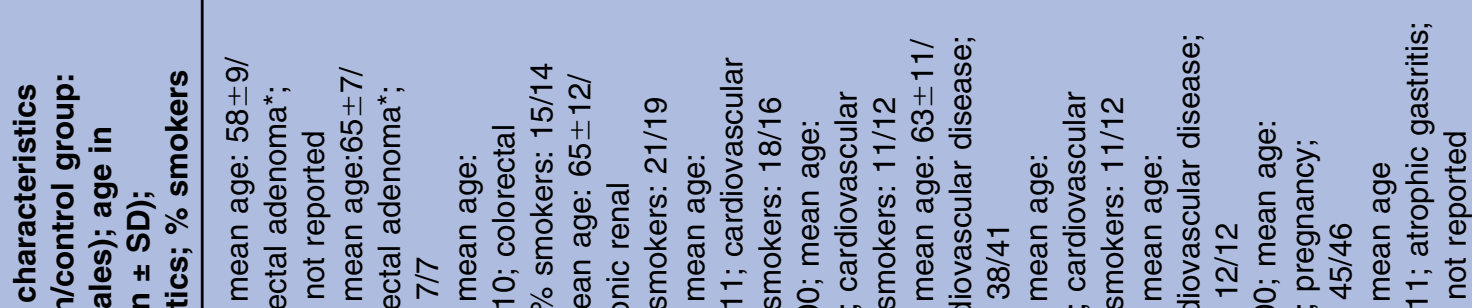

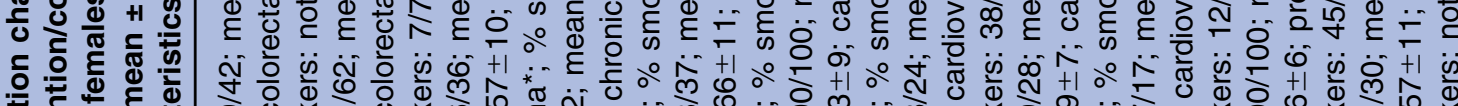

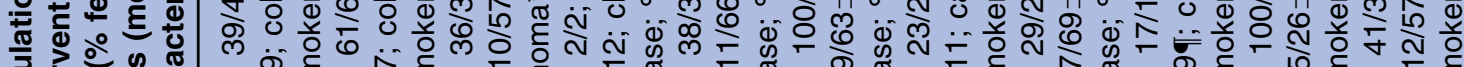

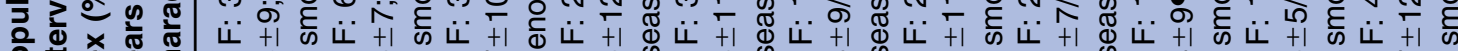
贾.

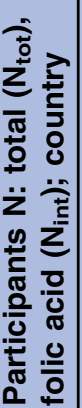

Y.

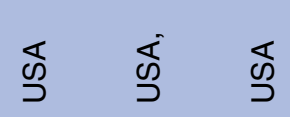

产

क

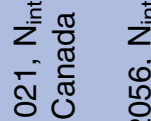

ชูำ

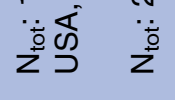

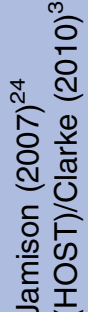

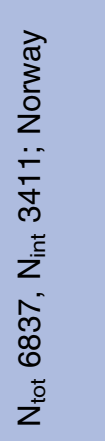

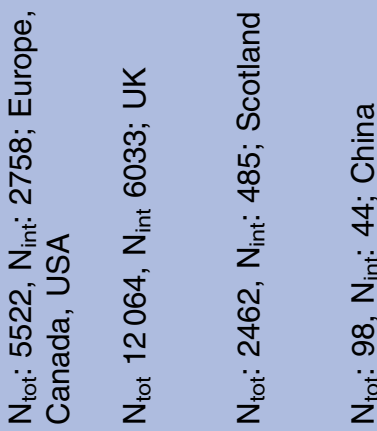

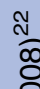

$\stackrel{\infty}{\stackrel{0}{\circ}}$

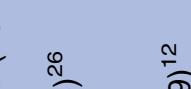

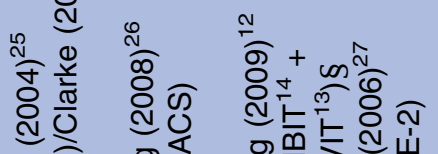

空

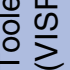

离感

等

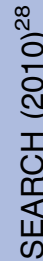

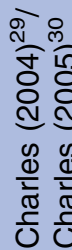

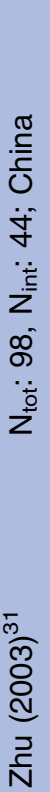

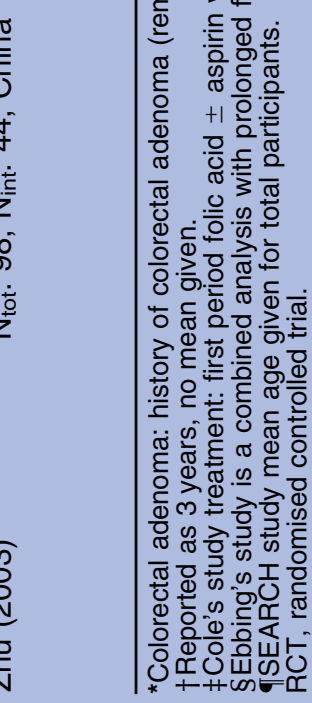




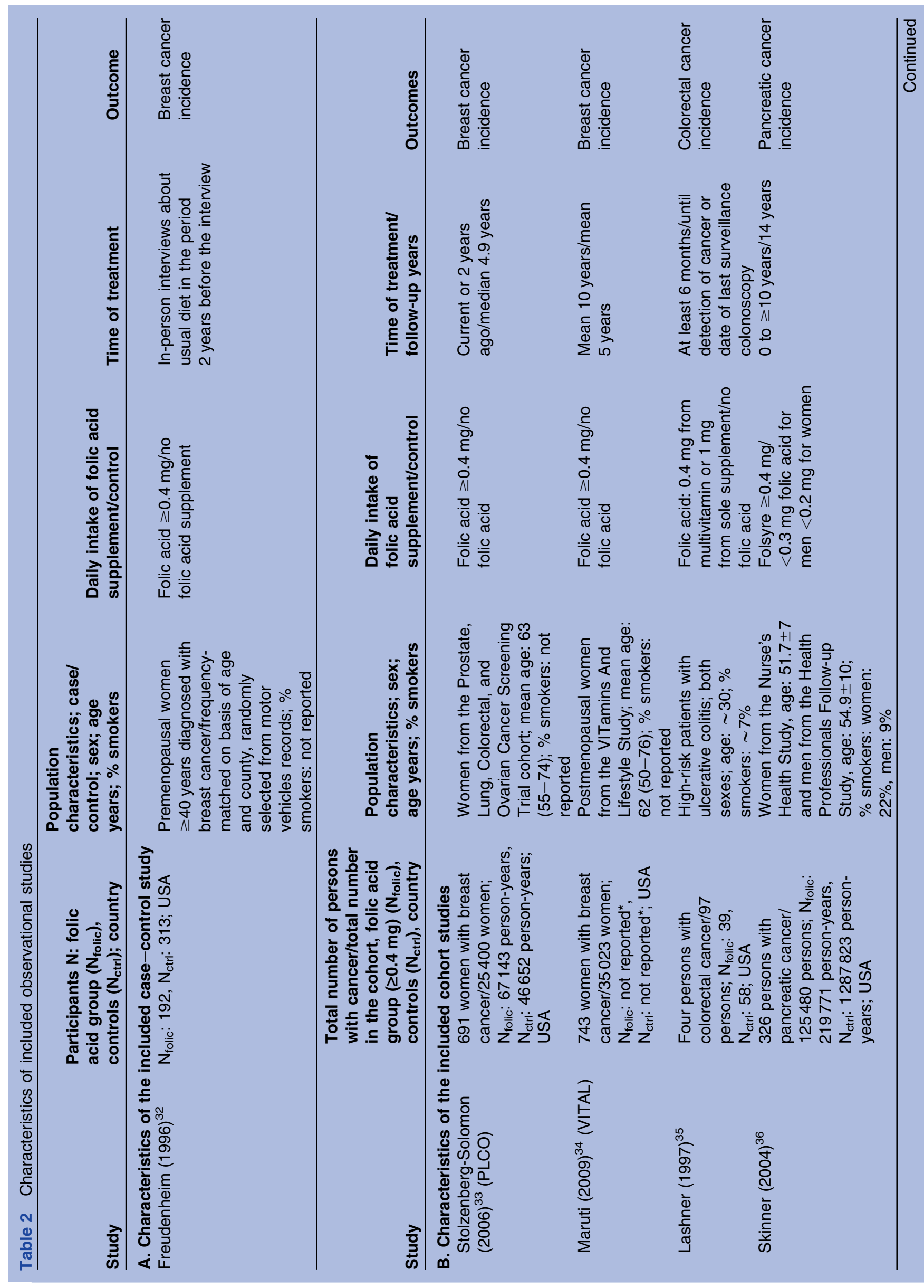




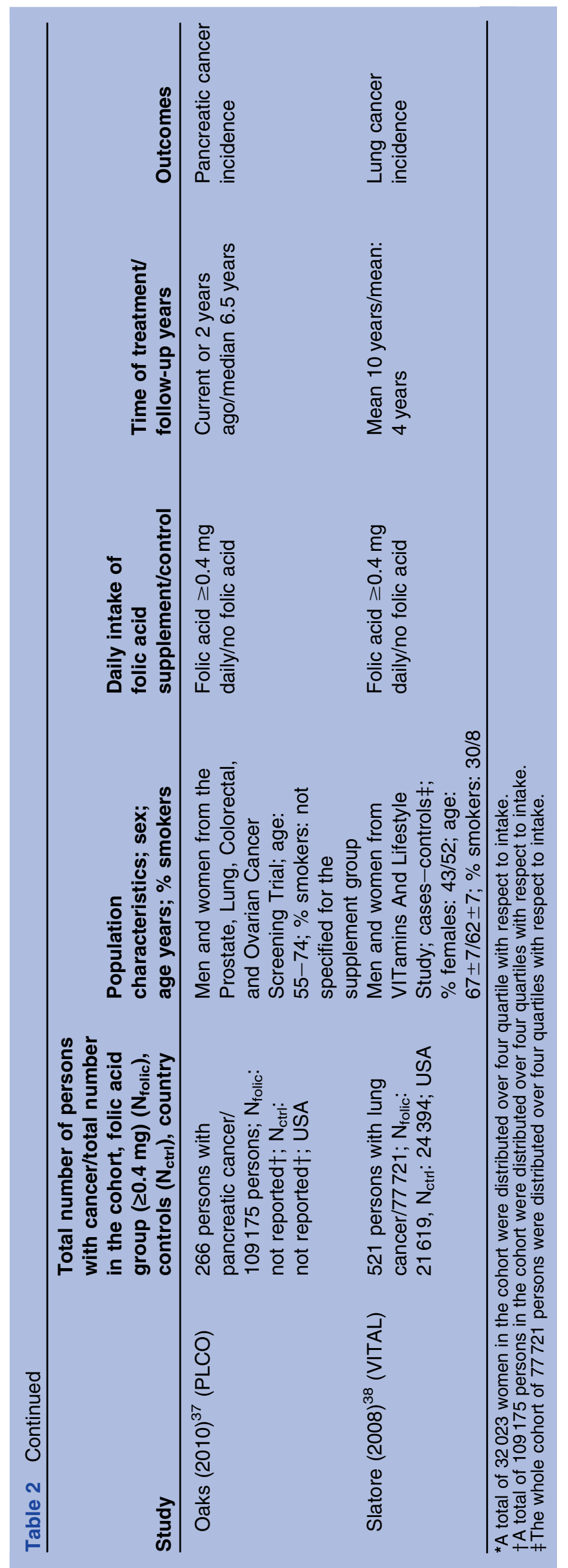

preventing fractures in older people, with cancer as secondary outcome. ${ }^{39}$ The other is a prolonged post-trial follow-up of the Norwegian studies WENBIT and NORVIT up to $2014,{ }^{40}$ for which we have data up to 2007 included in our analysis. ${ }^{12}$

\section{Excluded studies}

Two hundred and twenty-five studies judged to be relevant from screening of title/abstract were excluded after full-text examination. List of excluded articles is available at the web pages of the Norwegian Knowledge Centre for the Health Services. ${ }^{18}$ Eighty-nine studies were excluded due to missing or too low folic acid supplement intervention, that is, the study did not report data on folic acid supplements, only on dietary folate (83 studies) or supplement dose was below $0.4 \mathrm{mg}$ /day (six studies). In 95 studies, data were incomplete by either no dose specification on folic acid supplementation or lacking cancer outcome data for folic acid supplements (eg, risk was given for total folate intake, not for folic acid per se). Additionally, 41 studies were excluded due to other reasons, such as lack of a control group or lacking data on cancer development or mortality.

\section{Methodological quality}

Generally, the risk of bias in the included RCTs was low. All the RCTs, except two, had low risk of bias, that is, they had adequate sequence generation, allocation concealment, blinding and follow-up. The two remaining trials had high ${ }^{29}$ and unclear ${ }^{31}$ risk of bias, respectively, mainly due to inadequate or unclear reporting of sequence generation and allocation concealment. These two trials reported data on cancer mortality ${ }^{29}$ and gastrointestinal cancer, ${ }^{31}$ not on overall cancer incidence, and thus do not influence our overall estimate for this end point. The quality of the evidence for the individual end points was evaluated by use of GRADE. The outcomes from the RCTs generally had high quality for cancer incidence (high for total, colorectal, lung and prostate cancers; and moderate for breast cancer). For cancer mortality, the quality ranged from very low (breast), low (colorectal and prostate) to moderate (total and lung cancer mortality). The most common reason for lower quality was the very low number of events. The quality of the outcomes from the observational studies varied from low to very low.

\section{Cancer incidence}

The pooled effect estimates from $10 \mathrm{RCTs}^{11} 1314$ 22-28 reporting total cancer incidence with folic acid supplementation versus placebo were borderline significant with an RR of 1.07 (95\% CI 1.00 to 1.14 ) (figure 2A). A total of 3515 incident cancers were detected among 38233 participants. No heterogeneity across studies was detected in the analysis $\left(\mathrm{I}^{2}=0 \%\right)$. The funnel plot of this analysis seemed symmetrical (figure 2B); hence, we have no indication of publication bias based on this analysis. Sensitivity analyses on trial level (table 3) showed 


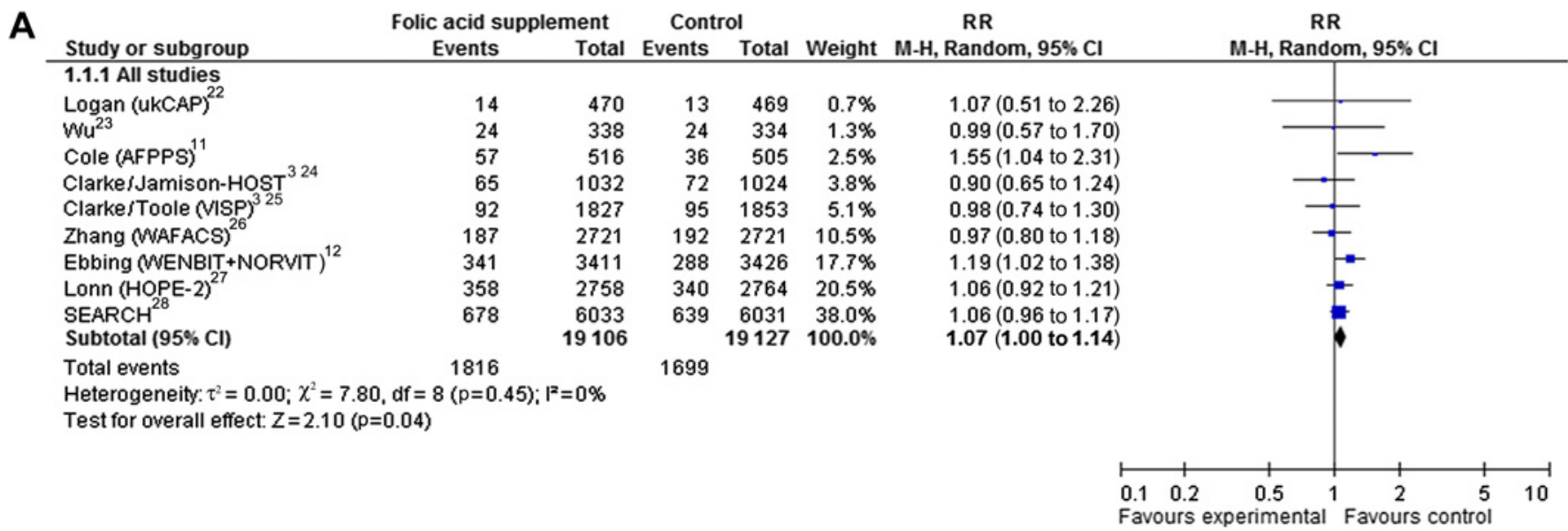

B

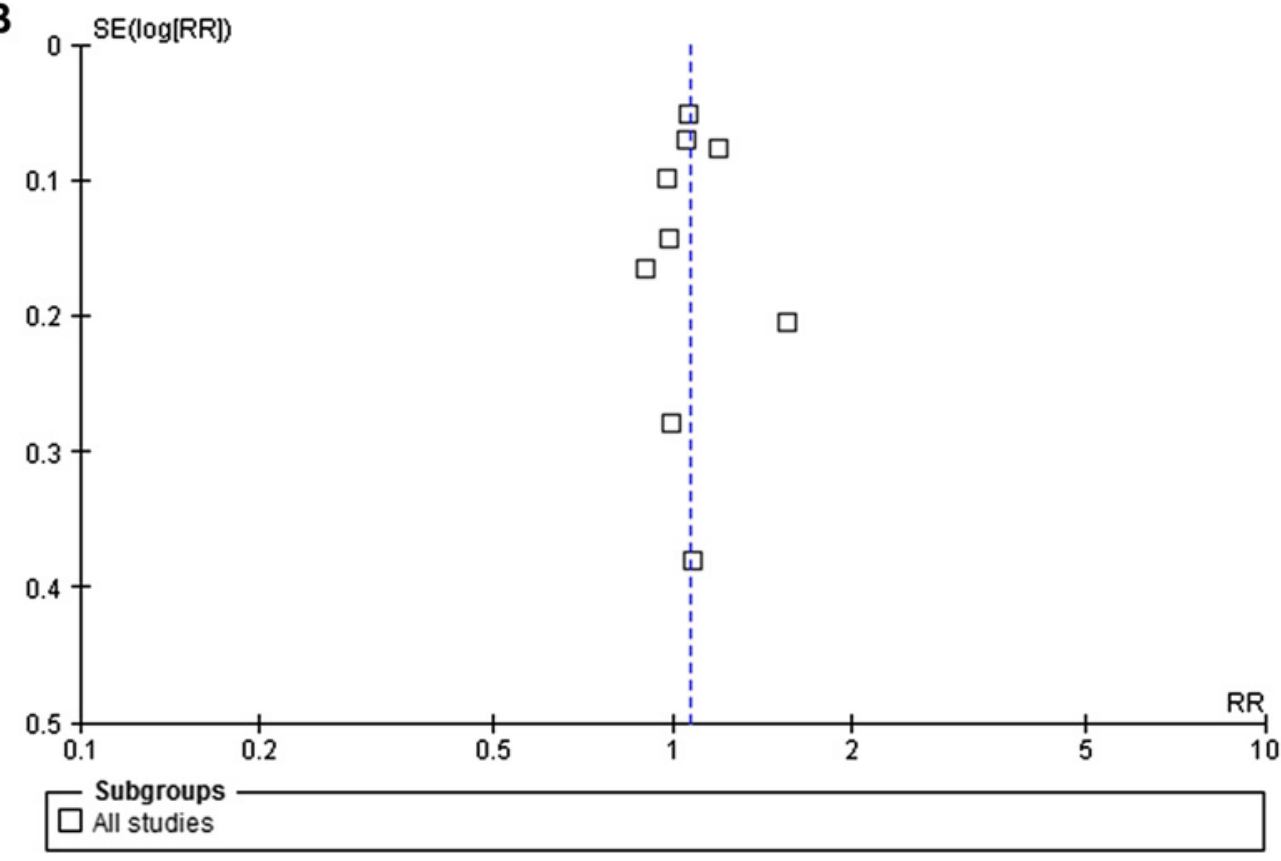

Figure 2 Randomised controlled trials that compare folic acid supplements $\geq 0.4 \mathrm{~g} / \mathrm{day}$ with placebo/control treatment with respect to total cancer incidence. (A) Forest plot showing meta-analysis. (B) Funnel plot of effect estimates plotted against SEs (on a reversed scale).

borderline increased risk of cancer development after folic acid supplementation in the four studies including $>70 \%$ of men (RR $1.08,95 \%$ CI 1.00 to 1.16 ) and in the two studies including $>30 \%$ of current smokers (RR $1.19,95 \%$ CI 1.02 to 1.38 ). Sensitivity analysis on comorbidity by separating studies in populations with a history of adenoma from populations with cardiovascular disease did not yield significant increased risk for developing cancer with folic acid supplementation in either group. Distributions of age and body mass index were very similar between the studies; thus, sensitivity analysis on study level by those factors was not feasible. Due to lacking data, we were not able to perform sensitivity analyses on alcohol consumption, family history of cancer or physical activity. Sensitivity analyses on folic acid dosage showed increased risk in the four studies, with a dose from 0.4 to $1 \mathrm{mg}$ (RR 1.21, 95\% CI 1.06 to
1.38) but not in those with folic acid doses above $1 \mathrm{mg}$. Folic acid exposure time of $<60$ months did not yield significant risk differences between the groups. Longer follow-up time, however, yielded borderline statistical significant increased cancer risk in the folic acid supplemented group, with an RR of 1.09 (95\% CI 1.00 to 1.18) in the six studies with $>60$ months of follow-up. Folic acid supplements given in coadministration with other B vitamins ${ }^{12}{ }^{24-28}$ did not show any significant difference between the groups. When administered together with aspirin, ${ }^{11}{ }^{22}$ a borderline significant increased risk was shown in the folic acid groups compared to the control groups (RR 1.43, 95\% CI 1.00 to 2.03). Two of the RCTs ${ }^{24}{ }^{26}$ were done in the USA after introduction of fortification. Sensitivity analysis of those two showed no significant difference between the groups (table 3). 
Table 3 Sensitivity analyses on study level of population, intervention and time to outcome assessment

\begin{tabular}{|c|c|}
\hline Sensitivity analysis & RR $(95 \%$ Cl) \\
\hline All & $1.07(1.00$ to 1.14$)$ \\
\hline$<70 \%$ men $^{11} 22232526$ & $1.05(0.90$ to 1.23$)$ \\
\hline$>70 \%$ men $^{12} 242728$ & $1.08(1.00$ to 1.16$)$ \\
\hline$<30 \%$ smokers $^{11} 23-28$ & 1.05 (0.98 to 1.12$)$ \\
\hline$>30 \%$ smokers $^{12}$ & 1.19 (1.02 to 1.38$)$ \\
\hline$<15 \%$ smokers ${ }^{23} 26-28$ & $1.04(0.97$ to 1.13$)$ \\
\hline$>15 \%$ smokers ${ }^{11} 122425$ & $1.12(0.93$ to 1.35$)$ \\
\hline $\begin{array}{l}\text { History of colorectal } \\
\text { adenoma }^{112223}\end{array}$ & $1.28(0.95$ to 1.72$)$ \\
\hline $\begin{array}{l}\text { History of cardiovascular } \\
\text { disease }^{12} 24-28\end{array}$ & $1.06(0.99$ to 1.13$)$ \\
\hline $0.4-1 \mathrm{mg}$ folic acid/day ${ }^{11} 122223$ & $1.21(1.06$ to 1.38$)$ \\
\hline$>1 \mathrm{mg}$ folic acid/day ${ }^{24-28}$ & $1.03(0.96$ to 1.11$)$ \\
\hline$<5$ years exposure 12222425 & $1.10(0.97$ to 1.23$)$ \\
\hline$>5$ years exposure $112326-28$ & $1.06(0.97$ to 1.17$)$ \\
\hline$<5$ years follow-up 222425 & $0.95(0.78$ to 1.17$)$ \\
\hline$>5$ years follow-up $11122326-28$ & $1.09(1.00$ to 1.18$)$ \\
\hline $\begin{array}{l}\text { Folic acid given in combination } \\
\text { with other } B \text { vitamins } \\
1224-28\end{array}$ & 1.06 (0.99 to 1.13$)$ \\
\hline Folic acid given with aspirin ${ }^{1122}$ & $1.43(1.00$ to 2.03$)$ \\
\hline $\begin{array}{l}\text { Folic acid given in countries } \\
\text { with fortification } 2426\end{array}$ & 0.95 (0.81 to 1.13$)$ \\
\hline
\end{tabular}

Meta-analysis of the seven observational studies including all cancer types reported showed no difference in cancer incidence between the group taking folic acid supplements and abstainers (six cohort studies gave an RR of 1.03 , $95 \%$ CI 0.92 to 1.16 ; and one case-control study an RR of $0.96,95 \%$ CI 0.54 to 1.68$)$.

In RCTs reporting incident cancer type, prostate cancer was the most common cancer type. In six RCTs $^{13} 1423272841$ with 25738 male participants, 349 incident cases of prostate cancer were found among 12867 participants in the folic acid groups and 283 cases among 12871 participants in the control groups (RR $1.24,95 \%$ CI 1.03 to 1.49 ) (figure 3 ). None of the included observational studies reported on prostate cancer. No statistically significant augmented cancer incidence risk was shown in the meta-analyses of incidence of any other cancer types in RCTs or observational studies. This included meta-analyses of RCTs of cancer of the breast (RR $0.86,95 \%$ CI 0.65 to 1.14 , three RCTs), ${ }^{232627}$ colon and rectum (RR 1.00, 95\% CI 0.83 to 1.21, nine RCTs), ${ }^{11} 12 \quad 22 \quad 23 \quad 26-28 \quad 31$ haematological cancers (RR $1.16,95 \%$ CI 0.76 to 1.78 , four RCTs), ${ }^{12} 2628$ lung (RR 1.11, 95\% CI 0.92 to 1.33 , six RCTs) ${ }^{12} 2326-28$ and pancreas cancer ( $\mathrm{RR} 1.50,95 \% \mathrm{CI} 0.42$ to 5.31 , analysis of one RCT). ${ }^{26}$ Correspondingly, none of the observational studies showed any difference in cancer incidence between the groups ${ }^{32-38}$ as shown for breast cancer (RR 1.02, 95\% CI 0.75 to 1.39, two cohort studies $^{32}{ }^{34}$; and $0.96,95 \%$ CI 0.54 to 1.68 , one casecontrol study ${ }^{32}$ ), lung cancer (RR 0.99 , 95\% CI 0.79 to 1.24, one cohort study ${ }^{38}$ ), pancreas cancer (RR 1.12, $95 \%$ CI 0.90 to 1.40 , two cohort studies ${ }^{36} 37$ ) and colon and rectum cancer (RR $0.45,95 \%$ CI 0.05 to 3.92 , one cohort study ${ }^{35}$ ).

\section{Cancer mortality}

Total cancer mortality was reported in six RCTs, 1314 26-29 with a total of 1134 cancer-related deaths among 32327 participants. With the exception of one study in pregnant women, ${ }^{29} 30$ all studies were performed in populations of patients with cardiovascular disease. The pooled effect estimate of all studies (figure 4A) showed no significant increase in cancer mortality in folic acid groups compared to controls (RR 1.09, 95\% CI 0.92 to 1.30). Sensitivity analysis on trial level showed increased risk for cancer mortality after folic acid supplementation in studies with $>30 \%$ of smokers (RR $1.38,95 \%$ CI 1.10 to 1.72). This subgroup included 9299 participants from the combined analysis of two Norwegian RCTs ${ }^{12}$ (NORVIT $^{13}$ and WENBIT $^{14}$ ) after folic acid supplementation as secondary prevention of cardiovascular events and from a Scottish follow-up study ${ }^{29} 30$ after folic acid supplementation in pregnancy. Sensitivity analyses on sex, age, comorbidity, dose folic acid or time of follow-up did not yield significant risk increase in any group.

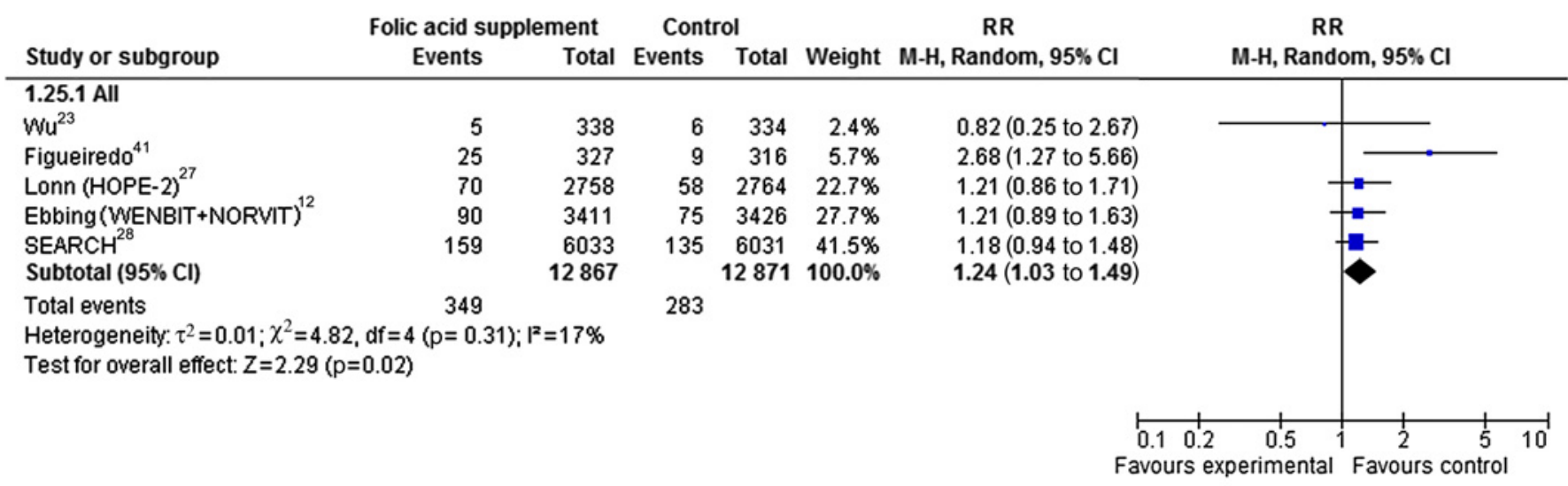

Figure 3 Forest plot of randomised controlled trials that compare folic acid supplements $\geq 0.4 \mathrm{~g} / \mathrm{day}$ with placebo/control treatment with respect to prostate cancer incidence. 


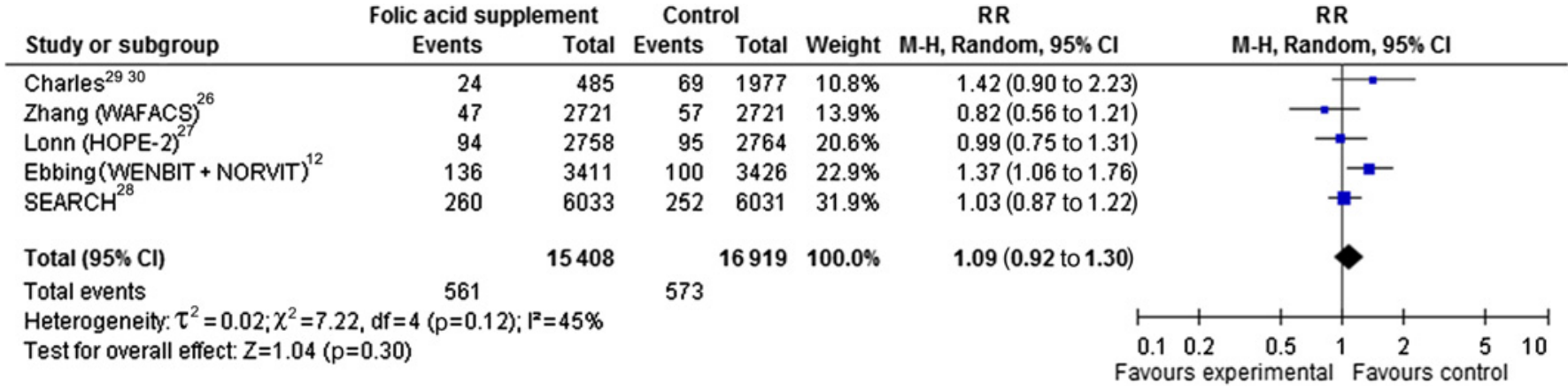

Figure 4 Forest plot of randomised controlled trials that compare folic acid supplements $\geq 0.4 \mathrm{~g} /$ day with placebo/control treatment with respect to total cancer mortality.

All meta-analyses of mortality of site-specific cancers had results that were not statistically significant in RCTs (data available at the web pages of the Norwegian Knowledge Centre for the Health Services ${ }^{18}$ ). None of the observational studies addressed mortality.

\section{DISCUSSION}

In the present systematic review, a meta-analysis of 10 RCTs showed a borderline significant incidence increase of overall cancer in the folic acid group compared to controls. Overall cancer incidence was not reported in the seven observational studies. However, meta-analysis of the seven observational studies including all cancer types reported showed no difference in cancer incidence between the group taking folic acid supplements and abstainers.

In sensitivity analyses, we identified four subgroups where folic acid supplementation increased cancer incidence and/or cancer mortality. These subgroups consisted of studies with a dose of folic acid from $0.4 \mathrm{mg}$ to $1 \mathrm{mg}$ /day, studies with $>30 \%$ of smokers, studies with $>70 \%$ of men and studies with a follow-up longer than 5 years. Whether smoking, gender, follow-up time or any other unreported reasons are the factors that contribute to this adverse effect of folic acid has not been studied.

\section{Comparison with other studies}

Our finding of no benefit, but a possible adverse effect from folic acid supplementation on cancer incidence is in line with reported results of studies on other nutrient supplements, including vitamin E, $\beta$-carotene (vitamin-A precursor) or selenium; all showing no or an adverse effect of supplementation in controlled clinical trials on cancer development. ${ }^{42}{ }^{43}$ A recent meta-analysis of folic acid supplements by Clarke and coworkers, in the 'B-Vitamin Treatment Trialists' Collaboration' ${ }^{3}$ with individual patient data, found no increased cancer risk in any subgroups. Our analysis differs from Clarke's by being a systematic review, thus including more studies (five more RCTs and seven observational studies) and by including more diverse populations than the seven B-vitamin trials in populations with cardiovascular disease included in the Clarke's study. In two studies included both in Clarke's meta-analysis and in ours, NORVIT and
WENBIT, we included data from the combined analysis with longer follow-up time published in $2009^{12}$; whereas Clarke et al only use cancer data from the original papers $^{13} 14$ with a shorter follow-up. When assessing possible harm, a longer follow-up time is beneficial in order to discover more potential cancer cases, as an augmented cancer risk after folic acid intervention may not be confined to a short post-trial time period.

In our sensitivity analyses of the RCTs, the studies with the largest proportions of smokers showed an increased risk of cancer incidence and cancer mortality associated with folic acid supplements. Smoking is a well-known risk factor for many cancers. Furthermore, unlike folate supplements, folate from diet seems to be protective for cancer development. ${ }^{7}$ Many smokers have poor dietary habits, and folate intake has been shown to be inversely associated with smoking duration. ${ }^{44}$ Recently, the European Prospective Investigation into Cancer and Nutrition, a large observational study, found a lower risk of developing lung cancer in former and current smokers within the highest quartile of serum folate compared to the lowest (OR 0.68, 95\% CI 0.51 to 0.90$).{ }^{45}$ No effect was apparent in never-smokers (OR 0.84, 95\% CI 0.43 to $1.65)$ or for colorectal cancer risk. ${ }^{46}$ Interestingly, and in line with a possible adverse effect of folic acid supplementation, another report from the European Prospective Investigation into Cancer and Nutrition study suggests a U-shaped relationship between plasma folate and risk of pancreatic cancer in both men and women, with highest risk for the lowest and highest serum quintile levels. $^{47}$

A large Swedish prospective study found that pancreatic cancer risk was reduced in people with diets rich in folate from foods but not from supplements. ${ }^{48}$ This is in line with other observational studies indicating a sourcespecific effect of folates with dietary folate being protective and folic acid supplements possibly being harmful or having no effect with respect to cancer risk. ${ }^{49-52}$ In one of the RCTs included in our analysis, ${ }^{41}$ folic acid supplementation of $1 \mathrm{mg}$ /day increased the risk of prostate cancer, while higher dietary folate and plasma folate levels among non-users of vitamin supplements were associated with decreased risk of prostate cancer. $^{53}$ 
It has been speculated that folate may be beneficial in primary prevention of cancer, but potentially harmful in the presence of early cancer. ${ }^{10}$ Accordingly, the antifolate methotrexate is an effective cytostatic drug used in the standard therapy of several cancer types. We performed sensitivity analyses for the folic acid supplemented population with a history of adenomas and the populations without such a history. This analysis showed no significant increased risk of colorectal cancer in either group. It should be noted, however, that we do not have data to support or weaken the interesting hypothesis of timing of folate supplementation as being important. The relative short latency time from exposure (folate supplementation) to cancer development reported from the recent Norwegian randomised trials ${ }^{12}$ suggests an effect on late carcinogenesis, as this short time indicates that a precancer situation might have been present during the intervention period.

In our sensitivity analyses of the RCTs, the studies with dose interval $0.4-1 \mathrm{mg} /$ day were associated with a higher risk of cancer development than studies with doses above $1 \mathrm{mg} /$ day, with RRs of 1.21 (95\% CI 1.06 to 1.38 ) and 1.03 (95\% CI 0.96 to 1.11 ), respectively. Our systematic search had no dose limitation and thus allowed us to search for all dose ranges, although our eligibility criteria specified doses $\geq 0.4 \mathrm{mg} /$ day. We identified no RCTs, but 11 observational studies with doses below $0.4 \mathrm{mg} /$ day reporting cancer incidence, thus allowing us post hoc to evaluate a possible dose-response pattern of observational studies including doses below $0.4 \mathrm{mg} /$ day. Six of these studies were already included in our review, as they also contained groups with daily intakes $\geq 0.4 \mathrm{mg},{ }^{32-34} 36-38$ and five were excluded from our main analyses due to daily dose of folic acid below $0.4 \mathrm{mg} .{ }^{49}{ }^{50}{ }^{54-56}$ No increased risk was found in the meta-analyses of doses below $0.4 \mathrm{mg}$ /day, with RR of 1.07 (95\% CI 0.92 to 1.26 ) for the cohort studies ${ }^{33} 3436-3849505456$ and 1.17 (95\% CI 0.58 to 2.33) for the case-control studies. ${ }^{32} 55$ Hence, our analyses did not indicate any dose-response pattern between folic acid dose and cancer incidence.

The reason for the increased risk in the dose interval $0.4-1 \mathrm{mg} /$ day has not been elucidated in our study, and we cannot exclude that other characteristics of these particular studies may be confounders. Although the smokers are randomised and evenly distributed between folic acid and placebo groups, one might speculate that a possible harmful effect of folic acid on smokers will be more evident in studies with more smokers.

A high alcohol intake is associated with higher incidence of several cancer types, including premenopausal and postmenopausal breast cancer. ${ }^{7}$ Folate intake or blood folate do not seem to influence breast cancer risk, but adequate folate may reduce the increased risk associated with alcohol consumption. ${ }^{57} \mathrm{~A}$ similar association between alcohol consumption and folate intake is reported in a prospective cohort study from the Nurses' Health Study on oral cancer risk in women. ${ }^{58}$ The effect of alcohol consumption on cancer development after folic acid supplementation was not possible to evaluate in the present study, due to restricted information in the original publications on alcohol intake.

When different cancer sites were assessed in our study, prostate cancer was the only cancer type found in the pooled analysis to have a significant risk increase after folic acid supplementation. There was some heterogeneity between the studies $\left(\mathrm{I}^{2}=17 \%\right)$, with one of the trials, AFPPS ${ }^{41}$ being an outlier compared to the other studies with an RR of 2.68 (95\% CI 1.27 to 5.66). However, the increased risk remained even if omitting this study from the pooled effect estimate (RR 1.19, 95\% CI 1.01 to $1.39, \mathrm{I}^{2}=0 \%$ ). In line with our results, a recent meta-analysis on serum folate and prostate cancer ${ }^{59}$ concluded that high serum folate concentrations were associated with increased prostate cancer risk. We may speculate on a specific effect of folic acid on prostate tissue rather than on cancer development in general due to differences in tissue and cell sensitivity to folic acid effects. Such potential tissue- and cell-specific differences in folic acid effects on cell biology need to be further explored in order to generate a molecular understanding for such a possible diverse tissue effect.

The major group recommended taking folic acid supplements today is women in childbearing age before and in the first trimester of pregnancy in order to prevent neural tube defects in the offspring. Only one of the studies in our review was performed in a population of pregnant women, the 36-year post-trial follow-up after an RCT in Scottish women taking folic acid in pregnancy. ${ }^{29}$ This study of Charles $e t$ al showed a significant increased risk for total cancer mortality (RR 1.70, 95\% CI 1.06 to 2.72) in pregnant women with folic acid supplementation, in the group taking the highest dosage of folic acid, $5 \mathrm{mg}$ /day, but not in the $0.2 \mathrm{mg}$ group (RR $1.20,95 \%$ CI 0.71 to 2.02). However, in our meta-analysis of total cancer mortality, where the study of Charles et al was analysed together with five other studies, no significant increase in total mortality was showed (RR $1.09,95 \%$ CI 0.92 to 1.30 ). The $5 \mathrm{mg}$ daily dose far exceeds the folic acid supplementation dosage recommended today for the female fertile population $(0.4 \mathrm{mg} /$ day $)$. It is worth noticing also that the proportion of smokers in the study of Charles et al was high (>40\%), which reflects smoking habits in the 1960s when the study was performed. Another study assessing cancer effects after folic acid supplements in pregnancy showed a reduced risk of childhood leukaemia (acute lymphoblastic leukaemia) in the offsprings. ${ }^{60}$ This study was, however, not included in our present analysis, as folic acid supplement dose was not specified.

The folic acid recommendations in order to reduce risk of fetal neural tube development are poorly followed by fertile women, as few women start folic acid intake prior to pregnancy. ${ }^{61}{ }^{62}$ Several countries, such as Canada and the USA, have started fortification of foods in order to increase periconceptional folic acid intake, aiming at reducing the incidence of neural tube defects. 
This food fortification strategy has been shown to efficiently reduce the incidence of open neural tube defects in Canada. ${ }^{63}$ Other countries, such as Norway ${ }^{64}$ and the UK, have not chosen this general food fortification strategy, mainly due to the unknown effects of augmented folic acid intake on the general population outside the target group of fertile women, such as masking of vitamin B12 deficiency in the older population and a possible risk of cancer development. Longitudinal studies on cancer development in countries that have introduced fortification of foods with folic acid could indicate whether fortification has similar risk of cancer as what seems to be the case for folic acid supplements. At present, there are no studies indicating that the current recommendation of folic acid supplementation (with the present recommended moderate dosages) to fertile women has any negative effects on the woman's or the offspring's future health.

Folic acid may alternatively be administered as 5methyltetrahydrofolate, as in the SU-FOL.OM3-trial, ${ }^{65}$ where patients in France with a history of ischaemic heart disease were randomised to either receive B vitamins (5-methyltetrahydrofolate, vitamin $\mathrm{B} 6$ and vitamin B12 or placebo) and $\omega-3$ fatty acids or placebo in a $2 \times 2$ factorial design. Mean duration of supplementation and of follow-up was 4.7 years. In this study, allocation to B-vitamins did not have any significant effect on cancer incidence (HR $1.19,95 \%$ CI 0.88 to 1.60 ). Adding this study to our meta-analysis of total cancer incidence would, however, not change the conclusions, with a pooled effect estimate (RR 1.08, 95\% CI 1.01 to 1.14).

\section{Strengths and limitations of the study}

Our review has several strengths. Our thorough systematic search makes it plausible that we have retrieved all relevant studies and can be assured not to miss important data. However, not all studies could be included in our meta-analyses due to unreported outcomes or dose of folic acid in supplements. The data extraction has been performed by individual reviewers and then controlled by others, which also strengthens our trust in this review. Additionally, most of the RCTs included are of high methodological quality, with a low risk of bias. This generally implies that we can be quite confident that the different study groups were randomised adequately and that the result from the studies can be trusted. Also, in some of the included studies, cancer cases found shortly after initiation of the study were excluded since it would be biologically implausible that these cases were related to the intervention.

The limited time of follow-up of most RCTs is a major limitation of our review because the time frame for cancer development might exceed the follow-up time in many RCTs. Actually, this review may be too conservative regarding estimating the long-term cancer risk associated with folic acid supplementation since regularly RCTs have a short follow-up time. This is also supported by our sensitivity analysis where the subgroup of studies with the longer follow-up time showed borderline increase in cancer risk with folic acid supplements, whereas the studies with shorter follow-up did not. However, when we add observational studies to broaden the evidence base and lengthen follow-up time, we do not find any additional risk difference between the groups.

Another limitation of our study is the lack of information on dietary patterns in the studied populations as the effect of supplements may vary according to the folate status of the population, for example, the proportion that are folate deficient. However, this is not thought to vary within one single study (RCTs) but may vary between studies and countries. In one of the RCTs, ${ }^{11}$ baseline dietary data were supplied in a separate paper, ${ }^{53}$ and although it showed an inverse association between high dietary intake and colorectal adenoma in the placebo group, thus indicating a protective effect, no association between dietary folate and colorectal adenoma was shown in the folic acid-supplemented group. The authors interpreted this as a beneficial effect of folate supplementation compared to deficiency but limited to some point of sufficiency, where increases provide no additional benefit. Our analysis may emphasise the need for pooling all relevant evidence into meta-analyses when appropriate and not trying to interpret conflicting results only based on one single RCT.

Another important limitation of our review is the selected populations in which the RCTs were performed, thus the findings may not be applicable to the population in general. Most participants included were treated in secondary prevention of adenomas and cardiovascular disease and may have increased cancer risk, for example, smoking is a common risk factor for cancer and cardiovascular disease. The one study with pregnant women had a higher proportion of smokers than is reported today. ${ }^{66}$ Effects of folic acid supplementation may vary among different subgroups, as demonstrated on trial level in our analysis. Our conclusions are based on RCTs with a low risk of bias, and randomisation of participants should minimise the problem of confounding.

We performed only regular meta-analyses and analysed sensitivity by dividing the results into groups. A more sophisticated way of investigating impact of different possible factors is to perform meta-regression. ${ }^{19}$ However, this is not recommended if $<10$ studies are included. ${ }^{19}$ Furthermore, we could not perform sensitivity analyses on some other variables that would be of interest, for instance on shorter periods of folic acid exposure that is more common in pregnancy.

More studies assessing cancer risk in the only population where folic acid supplementation is shown to be beneficial today (periconceptionally to fertile women to prevent neural tube defects) would have strengthened the analysis. However, the one long-term follow-up after such folic acid supplementation ${ }^{29}$ did not find an 
elevated mortality rate for any cancer (total cancers and breast cancer analysed separately) following the low supplementation dosage of $0.2 \mathrm{mg}$ daily.

Our review has not addressed dietary folate, and we cannot conclude on a possible 'source-specific' effect. A Cochrane review under preparation is addressing this issue. $^{67}$

\section{Conclusions and policy implications}

A meta-analysis of 10 RCTs showed a borderline significant increase in incidence of overall cancer in the folic acid group compared to controls. Overall cancer incidence was not reported in the seven observational studies. Longer follow-up than in ordinary RCTs might be needed to confirm this finding of a possible borderline significant increase in overall cancer incidence in the folic acid group compared to controls. Our analysis identified a very moderate, although statistically significant, elevated risk of prostate cancer after folic acid supplementation. A major limitation of our study is the highly selected population in which most of the studies were conducted (to prevent clinical events in heart disease patients), and the findings might not be applicable to the major groups currently recommended to take folic acid supplements, that is, women of childbearing age. Longitudinal studies on cancer development in countries that have introduced fortification of foods with folic acid, such as in the USA and Canada, could indicate whether fortification similar to supplementation moderately increases prostate cancer risk simultaneously with the positive effect of reducing neural tube defects.

Acknowledgements We thank research librarian Ingrid Harboe for her assistance in the literature searches and Ingvil von Mehren Sæterdal and Inger Natvig Norderhaug for their critical review of the protocol.

Funding This work was supported by the Norwegian Knowledge Centre for the Health Services.

Competing interests All authors have completed the Unified Competing Interest form, http://www.icmje.org/coi_disclosure.pdf (available on request from the corresponding author), and declare no competing interests for the submitted work.

Ethics approval This is a systematic review not requiring approval.

Contributors All authors contributed to the design of the systematic review, analysis and interpretation of the data. All authors had full access to all the data and take responsibility for the integrity of the data and the accuracy of the analysis. TNW, EP and TW extracted the data from the included studies. TNW drafted the manuscript, and the other authors critically reviewed the manuscript.

Provenance and peer review Not commissioned; externally peer reviewed.

Data sharing statement An extended version of this report in Norwegian is available at the web pages of the Norwegian Knowledge Centre for the Health Services www.nokc.no. Appendices to the extended report including search strategy, tables of included and excluded studies, data analyses on crude and adjusted data and GRADE files are available in English.

\section{REFERENCES}

1. Avdeling for Legemiddelepidemiologi Divisjon for Epidemiologi Nasjonalt Folkehelseinstitutt. Drug Consumption in Norway 2005-2009. 2010. http://www.legemiddelforbruk.no/ (accessed 17 Mar 2011).
2. Graham IM, Daly LE, Refsum HM, et al. Plasma homocysteine as a risk factor for vascular disease. The European Concerted Action Project. JAMA 1997;277:1775-81.

3. Clarke R, Halsey J, Lewington S, et al. Effects of lowering homocysteine levels with B vitamins on cardiovascular disease, cancer, and cause-specific mortality: meta-analysis of 8 randomized trials involving 37485 individuals. Arch Intern Med 2010;170:1622-31

4. Bazzano LA, Reynolds K, Holder KN, et al. Effect of folic acid supplementation on risk of cardiovascular diseases: a meta-analysis of randomized controlled trials. JAMA 2006;296:2720-6.

5. Lee M, Hong KS, Chang SC, et al. Efficacy of homocysteine-lowering therapy with folic Acid in stroke prevention: a meta-analysis. Stroke 2010;41:1205-12.

6. Cuskelly GJ, Mooney KM, Young IS. Folate and vitamin B12: friendly or enemy nutrients for the elderly. Proc Nutr Soc 2007;66:548-58.

7. World Cancer Research Fund/American Institute for Cancer Research. Food, Nutrition, Physical Activity and the Prevention of Cancer: a Global Perspective. World Cancer Research Fund/ American Institute for Cancer Research, 2007. http://www. dietandcancerreport.org/?p=er\&JServSessionldr004=jvchfng982. app244a

8. Duthie SJ. Folic acid deficiency and cancer: mechanisms of DNA instability. Br Med Bull 1999;55:578-92.

9. Prinz-Langenohl R, Fohr I, Pietrzik K. Beneficial role for folate in the prevention of colorectal and breast cancer. Eur J Nutr 2001:40:98-105.

10. Kim YI. Folate and colorectal cancer: an evidence-based critical review. Mol Nutr Food Res 2007;51:267-92.

11. Cole BF, Baron JA, Sandler RS, et al; Polyp Prevention Study Group Folic acid for the prevention of colorectal adenomas: a randomized clinical trial. JAMA 2007;297:2351-9.

12. Ebbing $\mathrm{M}$, Bonaa $\mathrm{KH}$, Nygard $\mathrm{O}$, et al. Cancer incidence and mortality after treatment with folic acid and vitamin B12. JAMA 2009;302:2119-26.

13. Bonaa $\mathrm{KH}$, Njolstad I, Ueland PM, et al. Homocysteine lowering and cardiovascular events after acute myocardial infarction. $N$ Engl J Med 2006;354:1578-88

14. Ebbing $\mathrm{M}$, Bleie $\mathrm{O}$, Ueland $\mathrm{PM}$, et al. Mortality and cardiovascular events in patients treated with homocysteine-lowering $\mathrm{B}$ vitamins after coronary angiography: a randomized controlled trial. JAMA 2008;300:795-804.

15. Liberati A, Altman DG, Tetzlaff $\mathrm{J}$, et al. The PRISMA statement for reporting systematic reviews and meta-analyses of studies that evaluate health care interventions: explanation and elaboration. PLOS Med 2009;6:e1000100.

16. Research Protocol: Cancer Risk With Folic Acid Supplements: A Systematic Review and Meta-Analysis. 2011. http://www.nokc.no. In press.

17. Cochrane Effective Practice and Organisation Filter of Care (EPOC) Group filter. In: Slik oppsummerer vi forskning. Håndbok for Nasjonalt kunnskapssenter for helsetjenesten 2009; Vedlegg 1: Tabeller med relevans for informasjonssøking. 2009. http://www. kunnskapssenteret.no. http://www.kunnskapssenteret.no/Verkt\% C3\%B8y/2139.cms (accessed 9 Apr 2011).

18. Cancer risk with folic acid supplements: a systematic review and meta-analysis. 2011. http://www.nokc.no. In press.

19. Higgins J, Green S. Cochrane Handbook for Systematic Reviews of Interventions. The Cochrane Collaboration. 2011. http://www. cochrane-handbook.org/ (accessed 29 May 2011).

20. Slik oppsummerer vi forskning. Håndbok for Nasjonalt kunnskapssenter for helsetjenesten 2009. 2009. http://www. kunnskapssenteret.no. http://www.kunnskapssenteret.no/Verkt\% C3\%B8y/2139.cms (accessed 9 Apr 2011).

21. Guyatt GH, Oxman AD, Kunz R, et al. What is "quality of evidence" and why is it important to clinicians? BMJ 2008;336:995-8.

22. Logan RF, Grainge MJ, Shepherd VC, et al. Aspirin and folic acid for the prevention of recurrent colorectal adenomas. Gastroenterology 2008;134:29-38.

23. Wu K, Platz EA, Willett WC, et al. A randomized trial on folic acid supplementation and risk of recurrent colorectal adenoma. Am J Clin Nutr 2009;90:1623-31.

24. Jamison RL, Hartigan P, Kaufman JS, et al. Effect of homocysteine lowering on mortality and vascular disease in advanced chronic kidney disease and end-stage renal disease: a randomized controlled trial. JAMA 2007;298:1163-70.

25. Toole JF, Malinow MR, Chambless LE, et al. Lowering homocysteine in patients with ischemic stroke to prevent recurrent stroke, myocardial infarction, and death: the Vitamin Intervention for Stroke Prevention (VISP) randomized controlled trial. JAMA 2004;291:565-75 
26. Zhang SM, Cook NR, Albert CM, et al. Effect of combined folic acid, vitamin $\mathrm{B} 6$, and vitamin $\mathrm{B} 12$ on cancer risk in women: a randomized trial. JAMA 2008;300:2012-21.

27. Lonn E, Yusuf S, Arnold MJ, et al; Heart Outcomes Prevention Evaluation (HOPE) 2 Investigators. Homocysteine lowering with folic acid and B vitamins in vascular disease. N Engl J Med 2006;354:1567-77.

28. Armitage JM, Bowman L, Clarke RJ, et al; Study of the Effectiveness of Additional Reductions in Cholesterol and Homocysteine (SEARCH) Collaborative Group. Effects of homocysteine-lowering with folic acid plus vitamin B12 vs placebo on mortality and major morbidity in myocardial infarction survivors: a randomized trial. JAMA 2010;303:2486-94.

29. Charles D, Ness AR, Campbell D, et al. Taking folate in pregnancy and risk of maternal breast cancer. BMJ 2004;329:1375-6.

30. Charles DH, Ness AR, Campbell D, et al. Folic acid supplements in pregnancy and birth outcome: re-analysis of a large randomised controlled trial and update of Cochrane review. Paediatr Perinat Epidemiol 2005;19:112-24.

31. Zhu S, Mason J, Shi Y, et al. The effect of folic acid on the development of stomach and other gastrointestinal cancers. Chin Med J (Engl) 2003;116:15-19.

32. Freudenheim JL, Marshall JR, Vena JE, et al. Premenopausal breast cancer risk and intake of vegetables, fruits, and related nutrients. J Natl Cancer Inst 1996;88:340-8.

33. Stolzenberg-Solomon RZ, Chang SC, Leitzmann MF, et al. Folate intake, alcohol use, and postmenopausal breast cancer risk in the Prostate, Lung, Colorectal, and Ovarian Cancer Screening Trial. Am J Clin Nutr 2006;83:895-904.

34. Maruti SS, Ulrich CM, White E. Folate and one-carbon metabolism nutrients from supplements and diet in relation to breast cancer risk. Am J Clin Nutr 2009;89:624-33.

35. Lashner BA, Provencher KS, Seidner DL, et al. The effect of folic acid supplementation on the risk for cancer or dysplasia in ulcerative colitis. Gastroenterology 1997:112:29-32.

36. Skinner HG, Michaud DS, Giovannucci EL, et al. A prospective study of folate intake and the risk of pancreatic cancer in men and women. Am J Epidemiol 2004;160:248-58.

37. Oaks BM, Dodd KW, Meinhold CL, et al. Folate intake, post-folic acid grain fortification, and pancreatic cancer risk in the Prostate, Lung, Colorectal, and Ovarian Cancer Screening Trial. Am J Clin Nutr 2010;91:449-55.

38. Slatore CG, Littman AJ, Au DH, et al. Long-term use of supplemental multivitamins, vitamin $\mathrm{C}$, vitamin $\mathrm{E}$, and folate does not reduce the risk of lung cancer. Am J Respir Crit Care Med 2008;177:524-30.

39. Netherlands Trial Register. Vitamin B12 and Folic Acid Supplementation for Preventing Fractures in Elderly People. 2011. http://www.who.int/ictrp/en/. http://apps.who.int/trialsearch/Trial. aspx?TriallD=NTR1333 (accessed 21 May 2011).

40. Haukeland University Hospital. NORVIT and WENBIT - Long-term Follow-up (NORVIT-WENBIT). 2010. http://ClinicalTrials.gov. http:// www.clinicaltrials.gov/ct2/show/NCT00671346 (accessed 22 May 2011).

41. Figueiredo JC, Grau MV, Haile RW, et al. Folic acid and risk of prostate cancer: results from a randomized clinical trial. J Natl Cancer Inst 2009;101:432-5.

42. Klein EA, Thompson IM Jr, Tangen CM, et al. Vitamin E and the risk of prostate cancer: the Selenium and Vitamin E Cancer Prevention Trial (SELECT). JAMA 2011;306:1549-56.

43. The Alpha-Tocopherol BCCPSG. The effect of vitamin E and beta carotene on the incidence of lung cancer and other cancers in male smokers. N Engl J Med 1994;330:1029-35.

44. Glynn SA, Albanes D, Pietinen P, et al. Colorectal cancer and folate status: a nested case-control study among male smokers. Cancer Epidemiol Biomarkers Prev 1996;5:487-94.

45. Johansson M, Relton C, Ueland PM, et al. Serum B vitamin levels and risk of lung cancer. JAMA 2010;303:2377-85.

46. Eussen SJ, Vollset SE, Igland J, et al. Plasma folate, related genetic variants, and colorectal cancer risk in EPIC. Cancer Epidemiol Biomarkers Prev 2010;19:1328-40.
47. Chuang SC, Stolzenberg-Solomon R, Ueland PM, et al. A U-shaped relationship between plasma folate and pancreatic cancer risk in the European Prospective Investigation into Cancer and Nutrition. Eur $J$ Cancer 2011:47:1806-16.

48. Larsson SC, Håkansson N, Giovannucci E, et al. Folate intake and pancreatic cancer incidence: a prospective study of Swedish women and men. J Natl Cancer Inst 2006;98:407-13.

49. Roswall N, Olsen A, Christensen J, et al. Source-specific effects of micronutrients in lung cancer prevention. Lung Cancer 2010;67:275-81.

50. Roswall N, Olsen A, Christensen J, et al. Micronutrient intake and risk of colon and rectal cancer in a Danish cohort. Cancer Epidemiol 2010;34:40-6.

51. Kim J, Kim DH, Lee BH, et al. Folate intake and the risk of colorectal cancer in a Korean population. Eur J Clin Nutr 2009;63:1057-64.

52. Baron JA, Sandler RS, Haile RW, et al. Folate intake, alcohol consumption, cigarette smoking, and risk of colorectal adenomas. J Natl Cancer Inst 1998;90:57-62.

53. Figueiredo JC, Levine AJ, Grau MV, et al. Colorectal adenomas in a randomized folate trial: the role of baseline dietary and circulating folate levels. Cancer Epidemiol Biomarkers Prev 2008;17:2625-31.

54. Tjønneland A, Christensen J, Olsen A, et al. Folate intake, alcohol and risk of breast cancer among postmenopausal women in Denmark. Eur J Clin Nutr 2006;60:280-6.

55. Shannon J, Phoutrides E, Palma A, et al. Folate intake and prostate cancer risk: a case-control study. Nutr Cancer 2009;61:617-28.

56. Roswall N, Olsen A, Christensen J, et al. Micronutrient intake and risk of urothelial carcinoma in a prospective Danish cohort. Eur Urol 2009:56:764-70.

57. Larsson SC, Giovannucci E, Wolk A. Folate and risk of breast cancer a meta-analysis. J Natl Cancer Inst 2007;99:64-76.

58. Shanmugham JR, Zavras Al, Rosner BA, et al. Alcohol-folate interactions in the risk of oral cancer in women: a prospective cohort study. Cancer Epidemiol Biomarkers Prev 2010;19:2516-24.

59. Collin SM, Metcalfe $\mathrm{C}$, Refsum $\mathrm{H}$, et al. Circulating folate, vitamin B12, homocysteine, vitamin B12 transport proteins, and risk of prostate cancer: a case-control study, systematic review, and metaanalysis. Cancer Epidemiol Biomarkers Prev 2010;19:1632-42.

60. Thompson JR, Fitz GP, Willoughby ML, et al. Maternal folate supplementation in pregnancy and protection against acute lymphoblastic leukaemia in childhood: a case-control study. Lancet 2001;358:1935-40.

61. Brække K, Staff AC. Periconceptional use of folic acid supplements in Oslo. Acta Obstet Gynecol Scand 2003;82:620-7.

62. Nilsen RM, Vollset SE, Gjessing HK, et al. Patterns and predictors of folic acid supplement use among pregnant women: the Norwegian Mother and Child Cohort Study. Am J Clin Nutr 2006;84:1134-41.

63. Ray JG, Meier C, Vermeulen MJ, et al. Association of neural tube defects and folic acid food fortification in Canada. Lancet 2002;360:2047-8.

64. Smeland S, Holven K, Løken EB, et al. Helsemessige gevinster av økt folatinntak. Hvordan nå ut til ønsket målgruppe? Norwegian Directorate of Health, 2007.

65. Galan P, Kesse-Guyot E, Czernichow S, et al; SU.FOL.OM3 Collaborative Group. Effects of $B$ vitamins and omega 3 fatty acids on cardiovascular diseases: a randomised placebo controlled trial. $B M J$ 2010;341:c6273.

66. The Health and Social Care Information Centre. Statistics on Smoking, England 2006. 2011. http://www.ic.nhs.uk. http://www.ic. nhs.uk/statistics-and-data-collections/health-and-lifestyles/smoking/ statistics-on-smoking-england-2006 (accessed 2 Jun 2011).

67. Cochrane Public Health Group. Protocol Under Development: Fortification of Wheat and Maize Flour With Folic Acid for Population Health Outcomes. 2010. http://www.cochrane.org. http://www2. cochrane.org/reviews/en/title_87197313613479766788100705065221. $\mathrm{html}$ (accessed 22 May 2011). 